\title{
Yale Observation Score for Prediction of Critical Illness in 3-36 Months Old Febrile Children
}

\author{
Dr Karuna Thapar ${ }^{1}$, Dr Preeti Malhotra ${ }^{2}$, Dr Ishpreet Singh ${ }^{3}$
}

\begin{abstract}
Introduction- Combining the laboratory tests with a pediatrician's self-judgmental score is thought to aid in diagnosing serious illness. Yale Observation Scale is one such observational score studied worldwide. Study Design- Prospective, hospital based, cross- sectional study. Material and Methods- 100 consecutive children 3-36 months of age with rectal temperature $>101 F$ were enrolled and YOS scoring done. This was followed by physical examination and extensive laboratory testing with $\mathrm{CBC}$, PBF, Urine and stool routine/microscopy, chest $x$-ray, CRP, ESR and blood cultures. The primary outcome was analysis of sensitivity, specificity, positive and negative predictive values of YOS scale in predicting critical illness while the secondary outcome was determination of vital parameters and laboratory findings which could reflect as "red flag " signs for critical illness. Results- YOS score of 10 on the ROC curve had 92.3 $\%$ Sensitivity, 44.2\% Specificity, Positive Predictive Value (PPV) $51.4 \%$ and Negative Predictive Value (NPV) $90 \%$ for intensive care requirement as demonstrated by percentage PICU admissions while with respect to clinical outcome, it had a sensitivity of $100.0 \%$, specificity of $32.9 \%, P P V 12.86 \%$ and NPV 100\%. Mean heart rates and respiratory rates were statistically positive "red flags" while mean temperature elevation, TLC, ESR and CRP levels had negative results. Conclusion- YOS score is very useful in ruling out critical illness in 3-36 months age group at cut-off value of 10 while only significantly higher scores( $>16)$ depict essentially serious illness and poorer outcome.
\end{abstract}

Keywords: YOS, specificity, sensitivity, critical , febrile ,total leucocyte count

\section{Introduction}

Fever is among the most common presenting complaints of children and infants presenting to the emergency department ${ }^{1}$. Fever represents a normal physiologic response that may result from the introduction of an infectious pathogen into the body and is hypothesized to play a role in fighting and overcoming infections ${ }^{2,3}$. In some cases, fever is a response to a serious or potentially life-threatening infection.

The challenge for emergency physicians is differentiating the vast majority of pediatric patients presenting with a fever who will have an uneventful course from the indeterminate few who have serious infections with the risk of mortality and long-term morbidity. A pediatrician makes a judgment of the degree of illness (severity) of a febrile child based on observation prior to history and physical examination. In young febrile children, differentiation between bacterial and non- bacterial causes of fever is necessary owing to a high incidence of viral infections and the fact that fever may also be due to bacteremia even in absence of localizing signs. Untreated bacteremia can cause serious complications including death, and hence an early diagnosis of bacteremia in a febrile child is crucial in reducing childhood mortality. Consequently, a pediatrician relies on clues gained prior to physical examination that might be indicators of the presence of a serious illness.

In this regard, use of acute Illness Observation Scale (AIOS) or Yale Observation Score (YOS) - a generic illness severity scale- represents a distinctive paradigm drawing on simple observations (based on toxic appearance) instead of complex symptomatology, aiming for wholeness rather than details and encompassing the entire not just the ends of sickness continuum. ${ }^{4,5}$

AIOS / YOS (a 3 point scale for six ordinal variables and total score range of 6 to 30 ) is a validated clinical index of quantifying risk of serious infections in children 36 months or younger with febrile illnesses.

Table 1: Yale Observation Score

\begin{tabular}{|c|c|c|c|}
\hline $\begin{array}{c}\text { Observation } \\
\text { item }\end{array}$ & Normal (Score $=1)$ & $\begin{array}{c}\text { Moderate } \\
\text { Impairment } \\
\text { (Score }=3) \\
\end{array}$ & $\begin{array}{c}\text { Severe } \\
\text { Impairment } \\
(\text { Score }=5) \\
\end{array}$ \\
\hline $\begin{array}{l}\text { 1. Quality of } \\
\text { cry }\end{array}$ & $\begin{array}{c}\text { Strong with } \\
\text { normal tone OR } \\
\text { Content and not } \\
\text { crying } \\
\end{array}$ & $\begin{array}{c}\text { Whimpering OR } \\
\text { Sobbing }\end{array}$ & $\begin{array}{c}\text { Weak OR } \\
\text { Moaning OR } \\
\text { High pitched }\end{array}$ \\
\hline $\begin{array}{l}\text { 2. Reaction } \\
\text { to parent } \\
\text { stimulation } \\
\end{array}$ & $\begin{array}{c}\text { Cries briefly then } \\
\text { stops OR Content } \\
\text { and not crying }\end{array}$ & Cries off and on & $\begin{array}{c}\text { Continual cry OR } \\
\text { Hardly responds }\end{array}$ \\
\hline $\begin{array}{l}\text { 3. State } \\
\text { variation }\end{array}$ & $\begin{array}{c}\text { If awake } \rightarrow \text { Stays } \\
\text { awake OR If } \\
\text { asleep and } \\
\text { stimulated } \rightarrow \\
\text { wakes up quickly }\end{array}$ & \begin{tabular}{|c|} 
Eyes close \\
briefly then \\
awake OR \\
Awakes up with \\
prolonged \\
Stimulation \\
\end{tabular} & $\begin{array}{l}\text { Falls to sleep OR } \\
\text { Does not wake up }\end{array}$ \\
\hline 4. Color & Pink & $\begin{array}{c}\text { Pale extremities } \\
\text { OR } \\
\text { Acrocyanosis }\end{array}$ & $\begin{array}{c}\text { Pale OR } \\
\text { Cyanotic OR } \\
\text { Mottled OR } \\
\text { Ashen }\end{array}$ \\
\hline 5. Hydration & $\begin{array}{c}\text { Skin normal, eyes } \\
\text { normal AND } \\
\text { Mucous } \\
\text { membranes moist }\end{array}$ & $\begin{array}{c}\text { Skin, eyes- } \\
\text { normal AND } \\
\text { Mouth slightly } \\
\text { dry }\end{array}$ & $\begin{array}{c}\text { Skin } \\
\text { doughy/tented } \\
\text { AND Dry } \\
\text { mucous } \\
\text { membranes } \\
\text { AND/OR Sunken } \\
\text { eyes }\end{array}$ \\
\hline $\begin{array}{l}\text { 6. Response } \\
\text { (talk, smile) } \\
\text { to social } \\
\text { overtures }\end{array}$ & $\begin{array}{c}\text { Smiles OR Alerts } \\
(<2 \text { mo. })\end{array}$ & $\begin{array}{l}\text { Brief smile OR } \\
\text { Alerts briefly } \\
\quad(<2 \text { mo. })\end{array}$ & $\begin{array}{c}\text { No smile, Face } \\
\text { anxious/dull/ } \\
\text { expressionless } \\
\text { OR No alerting } \\
(<2 \text { mo. }) \\
\end{array}$ \\
\hline
\end{tabular}

Therefore the aim of the study was to validate the observation scale in predicting illness severity, initial therapeutic modalities, and clinical outcomes, by use of simple observational variables available at the time of triage, even before physical examination and help primary physician in 


\section{International Journal of Science and Research (IJSR) \\ ISSN (Online): 2319-7064}

Index Copernicus Value (2015): 78.96 | Impact Factor (2015): 6.391

deciding the urgency and level of care required. Also, as a secondary outcome all physical examination parameters and laboratory tests were scrutinised for their efficacy in detecting serious illness.

\section{Materials and Methods}

The present study is a prospective, hospital based, crosssectional study conducted on 100 consecutive febrile children aged 3 - 36 months who will be admitted to the pediatric ward of a tertiary care centre. Only those children who will have documented fever in the hospital - defined as rectal temperature $>101^{\circ} \mathrm{F}$ will be enrolled. Written informed consent will be taken from parents before enrolling. Children developing fever more than 8 hours after they are admitted to the hospital or are known to have an immunodeficiency state or who had been given antibiotics or sedatives would be excluded from the study.

\section{Type of Study:}

This is a prospective study to be conducted on consecutive patients fulfilling inclusion criteria to avoid any selection bias.

\section{Inclusion Criteria:}

1) All children between 3 months to 36 months admitted in pediatric ward /PICU of Sri Guru Ram Das Institute of Medical Sciences and Research

2) Rectal temperature $>38.3^{\circ} \mathrm{C}$ or $101^{\circ} \mathrm{F}$

\section{Exclusion Criteria:}

1) Children $<3$ months or $>36$ months.

2) Rectal temperature $<38.3^{\circ} \mathrm{C}$ or $101^{\circ} \mathrm{F}$.

3) Children who had been given antipyretics or sedatives.

4) Children developing fever more than 8 hours after admission.

5) Immune deficient patients

The rectal temperatures were measured at the first peak of fever, before administering any antipyretics, with a clinical mercury-in-glass rectal thermometer. Fever was defined as a rectal temperature of $>101^{\circ} \mathrm{F}$. This was followed by assessment of YOS scores with the child seated on the parent's lap or if necessary, on a warmed sheet in an undisturbed supine position on an examination table. The items, which require minimal or no observer interaction or intervention (e.g., color, state of wakefulness) were scored first, followed by other items requiring interaction. As a first step, the parent was asked to comfort the child by holding or talking. Every attempt was made to place the child in a state of quiet wakefulness prior to scoring the remaining items requiring stimulation. This was followed by relevant history including demographic details and clinical examination.

Blood was withdrawn for laboratory investigations. Maximum of $0.8 \mathrm{ml} / \mathrm{kg}$ of blood was drawn per patient. It was immediately incubated and cultured. Blood cultures with all the required aseptic precautions were withdrawn in the entire study population irrespective of the results of the YOS scores and before administering the antibiotics. Investigations like ESR, Peripheral blood smear, Urine routine \& microscopy, Stool routine \& microscopy, CRP, Chest X-ray and Blood culture were sent for all the patients.
The child was then admitted to Ward or PICU depending on the condition of the child. This was followed by case specific investigations. Outcomes were recorded as:

1 .Admitted to Ward and Recovered

2. Admitted to PICU and Recovered

3 Died

\section{Observations}

Analysis Software: SPSS $^{\mathrm{TM}}$ version 17.0 and Microsoft Office Excel ${ }^{\circledR} 2007$ were used for statistical analysis of recorded data. Categorical (qualitative) variables were sorted in Contingency Tables and compared by Chi-square test. Results were considered to be statistically significant if $p$ $\leq 0.05$. Point estimates and $95 \%$ confidence intervals were calculated for the sensitivity, specificity, positive and negative predictive values (PPV and NPV) for the use of YOS as a diagnostic test to predict serious illness and clinical outcome. Receiver operating characteristic curves (ROC) were used to obtain a cut-off point that maximizes the diagnostic accuracy of the YOS score.

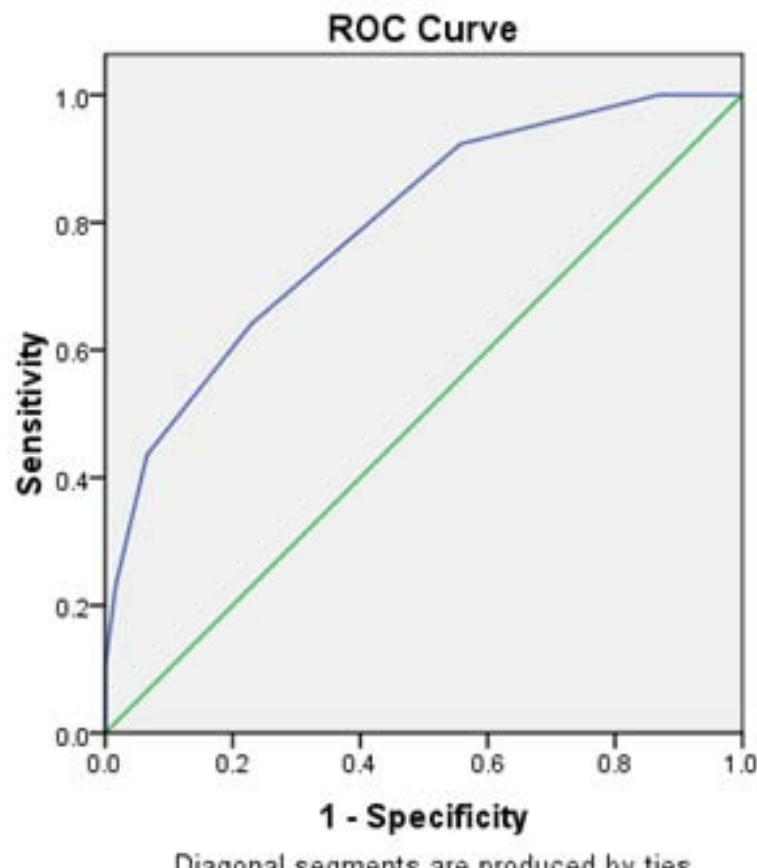

Figure 1: ROC Curve of Total Score with respect to WARD/ PICU Admission

YOS score of 10 had $92.3 \%$ Sensitivity, 44.2\% Specificity, with area under ROC curve of 0.597 for predicting intensive care requirement. Positive Predictive Value (PPV) for ward/PICU using score of 10 was $51.4 \%$ and Negative Predictive Value (NPV) for the same was 90.0\%. LR + (Positive Likelihood Ratio) and LR-(Negative Likelihood Ratio) were found to be 1.66 and 0.17 respectively. Thus, the diagnostic accuracy for prediction of Ward/PICU was found to be $63 \%$. This shows that total score was an extremely good measurement to predict serious illness (intensive care requirement) where YOS $\leq 10$ excludes the possibility of critical illness with great precision. However, YOS score of $>10$ was not specific to intensive care patients only but warrants caution and detailed investigations to assess severity of illness. 


\section{International Journal of Science and Research (IJSR) \\ ISSN (Online): 2319-7064}

Index Copernicus Value (2015): 78.96 | Impact Factor (2015): 6.391

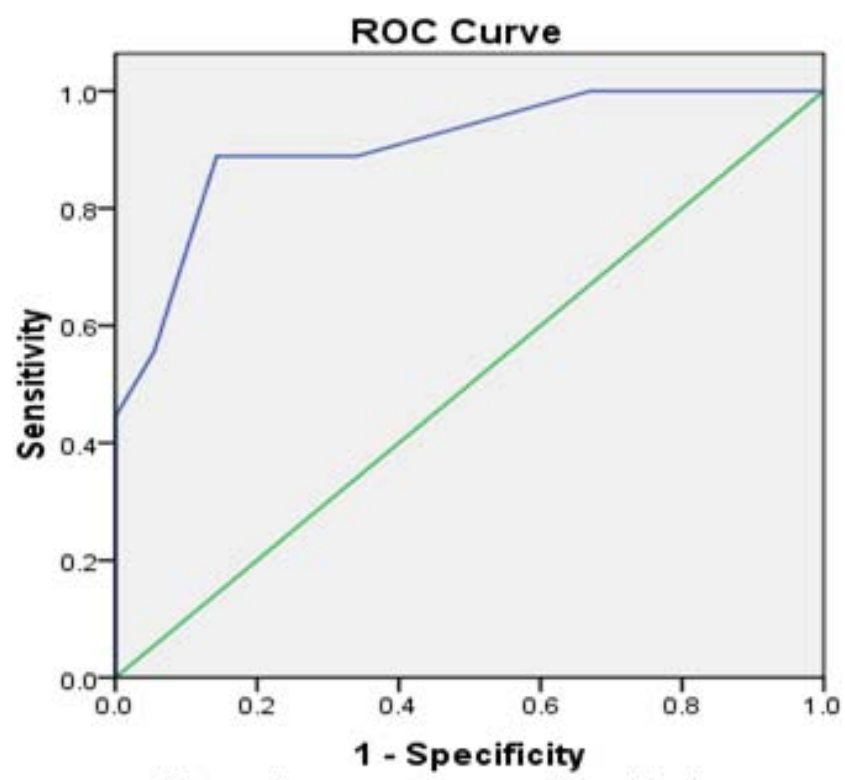

There were 9 deaths among those enrolled in this study. ROC curve was plotted and it was found that cut of score of 10 had specificity of $32.9 \%$ and sensitivity of $100 \%$ for predicting adverse outcome. Positive predictive value for outcome using score of 10 was $12.86 \%$ and negative predictive value for the same was $100.0 \%$, diagnostic accuracy being $39 \%$. Thus, it showed that cut off score of $\leq$ 10 had excellent sensitivity and negative predictive value for adverse outcome where a score of $\leq 10$ excludes any possibility of mortality. However, those with score $>10$ require further evaluation and laboratory investigations for assessment of serious illness.

Diagonal segments are produced by ties.

Figure 2: ROC Curve of Total Score with Respect to

Outcome

Table 1: Vital Parameters and Correlation with Critical Illness

\begin{tabular}{|c|c|c|c|c|c|c|}
\hline Vital Parameters & \multicolumn{3}{|c|}{$\begin{array}{l}\text { Ward/PICU Admission } \\
\text { p-value }\end{array}$} & \multicolumn{3}{|c|}{$\begin{array}{l}\text { Outcome } \\
\text { p-value }\end{array}$} \\
\hline \multirow{2}{*}{$\begin{array}{l}\text { Mean Heart } \\
\text { Rate }\end{array}$} & WARD & $126.28 \pm 16.97$ & \multirow[t]{2}{*}{0.000} & SURVIVAL & $130.15 \pm 20.19$ & \multirow[t]{2}{*}{0.000} \\
\hline & PICU & $143.9 \pm 27.32$ & & DEATH & $163.44 \pm 30.12$ & \\
\hline \multirow{2}{*}{$\begin{array}{l}\text { Mean Respiratory } \\
\text { Rate }\end{array}$} & WARD & $37.9 \pm 12.93$ & \multirow[t]{2}{*}{0.000} & SURVIVAL & $41.75 \pm 15.36$ & \multirow[t]{2}{*}{0.004} \\
\hline & PICU & $51.56 \pm 18.62$ & & DEATH & $58.22 \pm 22.89$ & \\
\hline \multirow{2}{*}{$\begin{array}{l}\text { Mean Temperature Elevation } \\
\text { from Baseline } 101^{\circ} \mathrm{F}\end{array}$} & WARD & $0.38 \pm 0.44$ & \multirow[t]{2}{*}{0.188} & SURVIVAL & $0.40 \pm 0.47$ & \multirow[t]{2}{*}{0.071} \\
\hline & PICU & $0.50 \pm 0.49$ & & DEATH & $070 \pm 0.39$ & \\
\hline \multirow[t]{2}{*}{ TLC } & WARD & $12278.6 \pm 4958.2$ & \multirow[t]{2}{*}{0.096} & SURVIVAL & $12806.3 \pm 6148.8$ & \multirow[t]{2}{*}{0.062} \\
\hline & PICU & $14693.3 \pm 9374.7$ & & DEATH & $17406.67 \pm 13121.2$ & \\
\hline \multirow[t]{2}{*}{ ESR } & WARD & $18.77 \pm 14.99$ & \multirow[t]{2}{*}{0.135} & SURVIVAL & $20.37 \pm 16.7$ & \multirow[t]{2}{*}{0.444} \\
\hline & PICU & $23.92 \pm 19.02$ & & DEATH & $24.89 \pm 17.98$ & \\
\hline \multirow[t]{2}{*}{ CRP } & WARD & $19.64 \pm 27.67$ & \multirow[t]{2}{*}{0.211} & SURVIVAL & $22.94 \pm 12.17$ & \multirow[t]{2}{*}{0.839} \\
\hline & PICU & $27.6 \pm 35.16$ & & DEATH & $20.73 \pm 12.64$ & \\
\hline
\end{tabular}

The mean heart rates and respiratory rates were significantly higher in patients admitted to PICU and those who suffered adverse outcome implying that both of these parameters acted as early warning signs of critical illness. However, mean temperature elevation, total lecuocyte count (TLC), erythrocyte sedimentation rate(ESR) and C-reactive protein(CRP) levels showed non- significant results.

\section{Discussion}

It is well recognised that paediatric in-patients who die or subsequently require intensive care often show signs of physiological and behavioural disturbance prior to arrest or collapse. ${ }^{6}$ As a result one of the recommendations in the Confidential Enquiry into Maternal and Childhood report "Why Children Die" stated: "For paediatric care in hospital we recommend a standardised and rational monitoring system with imbedded early identification systems for children developing critical illness - an early warning score". 7

The present study aimed to assess the efficacy of YOS (Yale Observation Score) in predicting severe illness and clinical outcome in febrile children, so that based on the YOS scores, a pediatrician can make a decision on the level and urgency of care required for that patient. As the response to observational parameters of YOS changes with neurological maturity of child, a variable age group of 3-36 months was selected for proving universal applicability of the score in the study. Also, as Yale observation score was found to be poor predictor in 0-3 months, this age group was excluded from the study. ${ }^{8}$

A single observer was recruited for calculating YOS scores of children bedside to avoid bias. Similarly, the decision of PICU admission was taken by the consultant alone who was blinded to the observer's YOS assessment. A procedural uniformity in recording the rectal temperatures prior to antipyretics, in applying YOS and in collection of the blood samples and use of regularly calibrated reliable thermometers minimized procedural and instrumental sources of variations. Indoor patients were enrolled, so that they can be followed up and outcomes noted.

The study population $(n=100)$ had a mean age of 13.70 months; $63 \%$ children being males. Young infants aged 3 to 5 months constituted the largest number of patients (25 of $100=25.00 \%) .61$ patients were managed in paediatric wards with uneventful recovery while 39 patients required intensive care out of which 9 patients died.

\section{Volume 6 Issue 1, January 2017




\section{International Journal of Science and Research (IJSR) \\ ISSN (Online): 2319-7064}

Index Copernicus Value (2015): 78.96 | Impact Factor (2015): 6.391

The mean YOS score of the overall study population was 12.84. The YOS scores were broadly ranging between 6 to 24 in the study with 8 patients having YOS $\leq 8,92$ patients having YOS $\geq 10,70$ patients having YOS $\geq 12$ and 21 patients having YOS $\geq 16$. Thus, most patients had YOS score between 10 to 16 in the study. As YOS 10 has been used as a benchmark for serious illness with significant sensitivity and specificity in previous studies, ${ }^{9,10}$ more than half of the febrile patients in our study scored higher than the cut off value of 10 to rule out serious illness.

Receiver operating characteristic curve (ROC) corresponded to a YOS score of 10 as cut-off with sensitivity of $92.3 \%$, specificity (44.26\%), ppv (51.43\%), npv (90\%), LR+ (positive likelihood ratio) 1.66 and LR- (negative likelihood ratio) 0.17 for ward/PICU admissions; diagnostic accuracy being $63 \%$. Similarly, with respect to outcome; the sensitivity, specificity, ppv, npv, LR + and LR - were $100 \%$, $32.97 \%, 12.86 \%, 100 \%, 1.49$ and 0.00 respectively; the diagnostic accuracy being $39 \%$. It can be inferred from above data that cut-off value of 10 performed excellently in its sensitivity and npv for serious illness. But higher cut-off values were needed to achieve appreciable specificity and ppv ( $>90 \%$ for YOS $\geq 16$ ). Hence, only at scores $\geq 16$ the patients had definite intensive care requirement and very high risk of suffering mortality.

Verbakel et al' 2013 retrospective data analysis showed similar results to our study where intermediate prevalence settings (5-20\%) had higher sensitivity (76\% and $88 \%$ in 2 databases) and a LR- of 0.3-0.7 compared to summary sensitivity of $96 \%$ and LR- of 0.085 in our study. ${ }^{10}$ Both the studies agree to validation of rule-out value of YOS in low and intermediate prevalence settings.

Another study by Van de bruel in 2007 classified red flag signs for serious illness by retrospectively compiling 1939 potentially relevant studies on serious children in developed countries where Yale Observation Scale was found to have little value in confirming (positive likelihood ratio range 1.10-6.70) or excluding (negative likelihood ratio range $0.16-0.97)$ the possibility of serious infection. This study was firstly done on children of developed nations, and secondly designed differently, hence could have resulted in different results from our study. ${ }^{11}$

There is lack of prospective data on YOS validation for serious illness till date with most studies being conducted on validation of YOS in bactaraemic febrile population. However, in ou study, critical illness whatever be the causative etiology was correlated to YOS observational score which is more realistic in the scenario of low and intermediate bacteraemia prevalence settings for validation and utilisation of YOS scale.

Mean heart rates and respiratory rates were significantly higher in patients requiring PICU admission ( $p$-values 0.000 each) and those suffering adverse outcome ( $\mathrm{p}$-values 0.000 and 0.004 respectively). However, temperature elevation showed non- significant correlation to critical illness parameters, namely intensive care need and adverse outcome (p-values 0.188 and 0.071 respectively). These results suggest that heart rate and respiratory rates offer fairly good clinical predictive value for serious illness as compared to mean temperature elevation. Also the YOS scores relate to patient's vital parameters excellently and both should be used together to increase the diagnostic precision.

Bhavneet Bharti et al's study ${ }^{12}$ also demonstrated similar results that total score on AIOS showed highly significant correlations with selected clinical characteristics at admission like grade of fever $(\mathrm{p}<0.01)$, respiratory rate $(\mathrm{p}$ $<0.01)$, heart rate $(0.01)$ and hence, outcome of febrile children.

Griffin MP et al conducted another study in 2001 where abnormal HRC (Heart rate characteristics) were found 24 hours before clinical suspicion of septicaemia in infants admitted to the University of Virginia over a period of 4 years. There were 46 episodes of culture-positive sepsis in 40 patients and 27 episodes of culture-negative sepsis-like illness in 23 patients. The infants in the sepsis and sepsislike illness groups had increasingly abnormal HRC for up to 24 hours preceding their abrupt clinical deterioration. The abnormal HRC were reduced baseline variability and shortlived decelerations in HR. These abnormalities led to significant changes in HRC measures, for example, the third moment (skewness: $.59+/-.10$ for sepsis and $.51+/-.12$ for sepsis-like illness, compared with - .10+/- .13 for control over the 6 hours before abrupt deterioration). Thus, heart rate is a vital parameter which can be ominous of serious infections in infants. ${ }^{13}$

In a systemic review by Opiyo $\mathrm{N}$ et al, it was concluded that the following clinical signs - alone or in combination-are likely to be the most valuable in identifying infants at risk of severe illness warranting hospital-level care: history of feeding difficulty, history of convulsions, change in level of activity, fast breathing/respiratory rate $\geq 60$ breaths per minute, severe chest indrawing, grunting and cyanosis. ${ }^{14}$

Prior to the conjugate vaccine era (ie, 1990 for Haemophilus influenzae type b Hib, and 2000 for Streptococcus pneumoniae), the risk of serious infections was shown to increase with higher body temperatures. ${ }^{15}$ However, evidence is lacking for whether the height of fever correlates with the rate of serious illnesses in the post-conjugate vaccine era.

Investigatory parameters like total leucocyte count, CRP, ESR were found to have statistically insignificant correlation with PICU admissions and adverse outcome ( $\mathrm{p}-$ values $>0.05$ ). This shows that in the population where majority of patients were non-toxic, non-ill; the laboratory investigations were insignificantly abnormal to predict critical illness. In such a scenario, YOS scaling proved an excellent measure for initial triage of febrile children.

In 2001, Galletto-Lacour et al. ${ }^{16}$ confirmed that total and differential leukocyte count performed poorly compared to PCT and CRP. WBC cut-off of $15 \times 10^{9} / 1$ had a sensitivity of $68 \%$ and specificity of $77 \%$. Bonsu et al. ${ }^{17}$ found that use of the WBC cut-off of $15 \times 10^{9} / 1$ would have yielded a sensitivity of only $45 \%$ and specificity of $78 \%$. Even the use

\section{Volume 6 Issue 1, January 2017




\section{International Journal of Science and Research (IJSR) \\ ISSN (Online): 2319-7064}

Index Copernicus Value (2015): 78.96 | Impact Factor (2015): 6.391

of a lower cut-off of $5 \times 10^{9} / 1$ would not detect $21 \%$ patients with bacteremia.

Similarly, Franz et al. considered a CRP value $>10 \mathrm{mg} / \mathrm{L}$, only in the presence of one (or more) clinical sign(s) compatible with infection, as a criterion to make a diagnosis of clinical septicemia in neonates. ${ }^{18}$ However, due to the time lag in the response of CRP to infection, some clinicians use it in combination with other biomarkers.

Pulliam et al. ${ }^{19}$ reported the results of a prospective study in 2001 examining the utility of CRP in evaluating febrile children. Seventy-seven children 1 to 36 months of age were enrolled in this study. CRP was found to be a much more useful biomarker than WBC count for this group of patients, with sensitivity of $79 \%$ and specificity of $91 \%$ at cut off $>$ $40 \mathrm{mg} / 1$ as compared to our study where $\mathrm{CRP}<5 \mathrm{mg} / 1$ was taken as cut-off as only 12 patients had CRP levels $>$ $40 \mathrm{mg} / \mathrm{l}$. Thus, CRP showed negative statistical results for prediction of critical illness at cut off of $5 \mathrm{mg} / \mathrm{l}$.

Galetto-Lacour et al. ${ }^{16}$ also evaluated the utility of CRP as a potential biomarker of infection. Children were prospectively enrolled at a pediatric emergency department in a European university hospital. A CRP cutoff of $40 \mathrm{mg} / \mathrm{l}$ resulted in a sensitivity of $89 \%$ and specificity of $75 \%$; more sensitive than Pulliam et al., ${ }^{19}$ but also less specific. Hence, in most of the studies, the sensitivity of CRP was shown to be low.

In the year 2000, research analysis by Jamuna $\mathrm{R}$ et al attempted to define clinical predictors of occult bacteraemia in an age group of 3-36 months attending paediatric outpatient department. In a 19 month study period, they concluded that high fever of temperature $>$ or $=102$ degrees $\mathrm{F}, \mathrm{ESR}>$ or $=15 \mathrm{~mm} /$ hour, and total leukocyte count $>$ or $=$ $15,000 / \mathrm{mm} 3$, in a child with AIOS score of $>$ or $=10$ may be considered for more detailed investigations and early intervention with antimicrobial therapy. Hence, the observational scoring and vital investigations together provided the ideal resources for confirming diagnosis, measuring severity of illness and deciding treatment. ${ }^{20}$

\section{Conclusion}

YOS scoring is a useful tool in early evaluation of critically ill children $>3$ months, in ruling out severe illness and intensive care requirement as well as their need for broad spectrum antibiotics. However, it must be used in conjuction with laboratory investigations and vital parameters for early triage of sick children in paediatrics as it increases diagnostic accuracy. YOS can be used to monitor admitted patients for early anticipation of deterioration or nonresponsiveness to ongoing treatment. In view of its simplicity, YOS is a tool which can be used by the junior residents, nurses and primary health care workers in initial evaluation of a sick, febrile child. Also, heart rate and respiratory rates must be monitored continuously in patients suspected to be gravely ill to diagnose impending critical illness. However, biomarkers alone do not offer any advantage and must be correlated with clinical parameters for evaluation of febrile children.

\section{References}

[1] Slater M, Krug SE. Evaluation of the infant with fever without source: an evidence based approach. Emerg Med Clin North Am.1999;17:97-126.

[2] Kai J. What worries parents when their preschool children are acutely ill, and why: a qualitative study. British Med J.1996; 313:983-86.

[3] Adam HM. Fever and host responses. Pediatr Rev.1996;17:330-31.

[4] Greenes DS, Harper MB. Low risk of bacteremia in febrile children with recognizable viral syndromes. Pediatr Infect Dis J.1999;18:258-61.

[5] Alpern ER, Alessandrini EA, Bell LM, Shaw KN, McGowan KL. Occult bacteremia from a pediatric emergency department: Current prevalence, time to detection, and outcome. Pediatrics.2000;106:505-11.

[6] Pearson, GA (Ed). Why Children Die: A Pilot Study 2006.

[7] England (South West, North East and West Midlands), Wales and Northern Ireland. London. CEMACH.2008.

[8] Mackowiak PA. Concepts of fever.Arch Int Med.1998;158:1870-81.

[9] Baker MD, Avner JR, Bell LM. Failure of infant observation scales in detecting serious illness in febrile, 4- to 8-week-old infants.Pediatrics.1990 Jun;85(6):1040-43.

[10] McCarthy PL, Sharpe MR, Spiesel SZ, Dolan TF, Forsyth BW, DeWitt TG et al. Observation scales to identify serious illness in febrile children. Pediatrics. 1982;70:802-09.

[11] Verbakel JY, den Bruel AV, Thompson M, Stevens R, Aertgeerts B, Oostenbrink $\mathrm{R}$ et al. How well do clinical prediction rules perform in identifying serious infections in acutely ill children across an international network of ambulatory care datasets? British Med Council .2013;11:10-5.

[12] Bruel V.D., Haj-Hassan T, Thompson M, Buntinx F, Mant D. Diagnostic value of clinical features at presentation to identify serious infection in children in developed countries: a systematic review. Lancet.2010 Mar;375(9717):834-45.

[13] Bharti B, Bharti S, Verma V. Role of acute illness observation score (AIOS) in managing severe childhood pneumonia. Indian Journal of Pediatrics.2007;74: 27-32.

[14] Griffin MP, Moorman JR. Toward the early diagnosis of neonatal sepsis and sepsis-like illness using novel heart rate analysis. Pediatrics. 2001 Jan;107(1):97-104.

[15] Opiyo N, English M. What clinical signs best identify severe illness in young infants aged 0-59 days in developing countries? A systematic review. Arch Dis Child.2011;96(11): 1052-59.

[16] Lee GM, Harper MB. Risk of bacteremia for febrile young children in the post-Haemophilus influenzae type b era. Arch Pediatr Adolesc Med.1998;152:624.

[17] Galetto-Lacour A, Zamora S, Gervaix A. Bedside procalcitonin and $\mathrm{C}$-reactive protein tests in children with fever without localizing signs of infection seen in a referral center. Pediatrics 2003;112(5):1054-60.

[18] Bonsu B, Harper M. Identifying febrile young infants with bacteremia: Is the peripheral white blood cell 


\section{International Journal of Science and Research (IJSR)}

ISSN (Online): 2319-7064

Index Copernicus Value (2015): 78.96 | Impact Factor (2015): 6.391

count an accurate screen? Ann Emerg Med 2003;42(2):216-25.

[19] Franz A, Steinbach G, Kron M, Pohlandt F. Reduction of unnecessary antibiotic therapy in newborn infants using interleukin-8 and C-reactive protein as markers of bacterial infections. Pediatrics 1999;104(3):447-53.

[20] Pulliam PN, Attia MW, Cronan KM. C-reactive protein in febrile children 1 to 36 months of age with clinically undetectable serious bacterial infection. Pediatrics 2001;108(6):1275-9.

[21] Jamuna R, Srinivasan S, Harish BN. Factors predicting occult bacteremia in young children. Indian $\mathrm{J}$ Pediatr.2000 Oct;67(10):709-11. 